\title{
O AMOR E A MEMÓRIA NO LIVRO X DAS CONFISSÕES DE SANTO AGOSTINHO
}

\section{THE LOVE AND MEMORY IN THE BOOK X OF CONFESSIONS OF SAINT AUGUSTINE}

\author{
Fabiano Veliq* \\ Ana Paula Ferreira Gomes**
}

\section{RESUMO}

A obra Confissões de Santo Agostinho traz, ao longo de seus capítulos, o processo de conversão do filósofo ao catolicismo, contando com reflexões a respeito de diversos assuntos relacionados à religião e sua expressão na vida dos homens em sociedade. No presente artigo, temos por objetivo focalizar nas temáticas do Amor e da Memória, por meio das quais Agostinho busca alcançar a Deus, abordadas, principalmente, no livro $\mathrm{X}$ das Confissões, temas esses de grande relevância na produção científica e filosófica até a atualidade. A princípio, tratamos do amor em suas diferentes formas, bem como de sua relação com as teorias platônicas e da psicanálise, traduzindo-se, também, pela ideia de desejo e falta. Seguimos para o exame da alma como parte constituinte do ser e a vinculação dela à memória, reconhecida por meio do processo de autoconhecimento do autor. O estudo da referida memória se dá por meio das metáforas apresentadas por Agostinho, sendo relevante, posteriormente, para o aprofundamento de questões como a temporalidade e a vida feliz. Por fim, discutimos as volúpias dos sentidos, que dialogam, mais uma vez, com a temática do amor.

PALAVRAS-CHAVE: Amor. Memória. Deus. Vida feliz.

\section{ABSTRACT}

The work Confessions of Saint Augustine brings, throughout its chapters, the process of converting the philosopher to Catholicism, with reflections on various issues related to religion and its expression in the lives of men in society. In this article, we aim to focus on the themes of Love and Memory, through which Augustine seeks to reach God, addressed, mainly, in Book X of the Confessions, themes of great relevance in scientific and philosophical production until today . At first, we deal with love in its different forms, as well as its relationship with Platonic theories and psychoanalysis, also translating into the idea of desire and lack. We move foward to examine the soul as a constituent part of being and its connection to memory, recognized through the author's self-knowledge process. The study of the referred memory occurs through the metaphors presented by Augustine, being relevant, later, for the deepening of issues such as temporality and Happy Life. Finally, we discuss the voluptuousness of the senses, which dialogue, once again, with the theme of love.

KEYWORDS: Love. Memory. God. Happy life.

O tema do amor e da memória em Santo Agostinho é extremamente amplo, de forma que uma abordagem exaustiva do assunto se torna por definição impossível. Nosso objetivo é muito

\footnotetext{
* Mestre em Filosofia da Religião pela FAJE e Doutor em Psicologia pela PUC Minas. Doutorando em filosofia pela UFMG. Prefoessor de Filosofia na PUC Minas. veliqs@ gmail.com.

** Graduanda em Psicologia pela PUC Minas. E-mail: anapaulaferreiragomes03@ gmail.com.
} 
mais modesto neste texto, ou seja, se constitui em tentar explicar a noção de amor e sua vinculação com o conceito de memória a partir dos temas trabalhados no livro X das Confissões de Santo Agostinho.

Agostinho inicia as considerações a respeito do amor, no livro $\mathrm{X}$, a partir do questionamento "o que amo, então, quando amo meu Deus?". Na insinuação de um diálogo com a natureza ao seu redor, o filósofo tenta encontrar um Deus que possa ser contido por ela, o que se traduz em uma percepção animista do Deus cristão. ${ }^{1}$

Santo Agostinho, ao falar do amor, retomará a ideia platônica de amor como busca descrito no $O$ Banquete de Platão (1977) e antecipará a ideia psicanalítica do amor como falta, embora a falta em Santo Agostinho não possa ser encarada da mesma forma que a falta para a psicanálise como proposta por Freud. Algo que é importante salientar é que Agostinho não é dependente apenas da noção de amor platônico, mas sabe-se que na sua juventude foi leitor de Cícero e do estoicisimo, nos quais já havia várias reflexões do amor e da continência; Plotino, o grande neoplatônico de quem Agostinho leu vários textos, era celibatário.

O amor para Santo Agostinho é appetere (um apetite), ou seja, é um movimento em direção a algo ou alguém. O amor é desejo, ou seja, o amor é uma busca que é tão natural ao homem quanto o é o desejo. Por isso para Agostinho o ser humano é um ser de desejo. ${ }^{2}$ Assim

\footnotetext{
${ }^{1}$ Essa ideia sobre Deus e a natureza será um tema muito importante em toda a história da teologia e da filosofia; ela também pode ser encontrada posteriormente na Kabala judaica, na tradição luriânica (advinda de Isac de Luria [1534-1572]). Sua mitologia indica Ein Sof que, desprovido de formas ou propósitos, e ao mesmo tempo condenado à eternidade, é tomado pelo desejo de criar a humanidade, preenchendo-a com seres que possuiriam tanto uma forma quanto um propósito de vida, dentro de sua finitude. Entretanto, a energia de sua existência preenchia todo o universo ao redor, de forma que Ein Sof teve de gerar um vazio dentro de si mesmo para dar início à sua criação, um espaço para fazer yesh (alguma coisa) de ayin (nada). Movimento esse conhecido como TsimTsum. A parte de si retirada foi depositada em um vaso que acabou não conseguindo suportar a luz ali guardada, de forma que se quebrou em muitas partes, provocando caos e a destruição do mundo em construção. Os fragmentos do desastre se misturaram à energia de Deus, formando um mundo humano desordenado e quebrado, salpicado com pontos da luz divina inicial por toda sua extensão. Dessa forma, os homens nascidos neste mundo estariam destinados a libertar essas pequenas lascas de luz por meio do estudo da Kabala. A luz liberta retornaria a Deus, tornando-o inteiro novamente. Aqui, vemos o processo de "vir a ser", de um Deus dependente dos homens para restaurar sua totalidade. Traduzindo as simbologias de Ein Sof, do vaso e da luz divina, podemos entender que, para a doutrina Cristã, Deus teve de criar um universo dentro de si, de tal forma que tudo que existe está condicionado e contido nEle. Por outro lado, é importante salientar que as criações não podem contê-lo, como prega o Panteísmo. Nesse sentido, podemos interpretar a passagem em que Agostinho (2017, p. 260) dialoga com a natureza: "Perguntei à massa do mundo sobre meu Deus, e ela me respondeu: 'Não sou eu, mas ele me fez'." Entende-se, aqui, que a natureza em si não retém a existência de Deus, mas, na verdade, foi feita acondicionada a Ele.

${ }^{2}$ Interessante notar que Santo Agostinho, em seu livro A graça (1999, cap. IV, p. 20) traz a noção paulina descrita em Romanos 8, 6 de que "o desejo da carne é morte, ao passo que o desejo do espírito é vida e paz.
}

Sapere aude - Belo Horizonte, v. 11 - n. 22, p. 577-588, Jul./Dez. 2020 - ISSN: 2177-6342 
como os animais o ser humano possui instintos e necessidades, mas apenas o homem é capaz de abrir mão desses instintos por um prazer (delectatio) superior.

Para Agostinho, o fato de o ser humano ser dotado de desejo aponta que ele é marcado pela falta, ou seja, ele está em busca de prazeres para a sua vida, e o maior prazer que ele busca é a vida feliz (beata vita), que é permeada pela alegria e apenas é alcançada em Deus. Para Agostinho, sabendo ou não, o homem sempre está em busca de Deus, pois é Deus aquilo que lhe falta. Essa falta de que trata Santo Agostinho é uma falta advinda do pecado do homem, ou a falta de Deus no coração do homem. A antropologia agostiniana parte do pressuposto de que o homem pecador é um homem carente de Deus, e a falta que ele experimenta é o não repouso de seu espírito em Deus. O “cor inquietum" agostiniano aponta exatamente para essa falta advinda do pecado, ou seja, a falta experimentada pelo homem é a falta de Deus, que só poderá ser preenchido pelo próprio Deus. O pecado original no homem ${ }^{3}$, no entanto, leva-o a diversas vezes errar o seu alvo, que é Deus, e ele passa então a desejar outras coisas que o afastam de Deus. O pecado original deforma o amor em um amor de si mesmo, em vez de ser, em primeiro lugar, amor de Deus.

Para a antropologia agostiniana há apenas um amor, pois o desejo do homem é apenas um. No entanto, esse amor pode assumir duas formas diferentes, dependendo do objeto ao qual esse amor visa. Segundo afirma Agostinho,

[...] o corpo (material) está mais sujeito à morte e, portanto, mais próximo do nada. Pelo que, o ser com alma, que pelo gozo material abandona a Deus, tende ao nada e esse é o mal (nequitia). Razão da queda do primeiro homem. Eis como a vida se torna terrena e carnal, e porque é também chamada terra e carne. Enquanto permanece nesse estado não possui o reino de Deus, e o objeto de seu amor lhe escapa. Isso porque ama o corporal que é menos do que a Vida. Devido a essa desordem, é corruptível o objeto de seu amor. (AGOSTINHO, 2002. p. $34)$.

O amor pode dar primazia a Deus, ou dar primazia a si mesmo amando as criaturas apenas pelo que elas podem oferecer. No primeiro caso, o amor é mediado pelo amor de Deus: eu amo as criaturas com um amor que as respeita, que me respeita e que me permite respeitar a Deus. Eu O

\footnotetext{
${ }^{3}$ A doutrina do pecado original é uma doutrina agostiniana que afirma que o homem já nasce com a semente do pecado fruto do pecado de Adão. Segundo Agostinho, depois da queda de Adão no jardim do Éden todos os homens herdaram de Adão o pecado e por isso já nascem marcados pelo pecado original. Essa doutrina foi adotada pela tradição católica e é um dos principais motivos para um dos sacramentos mais importantes no catolicismo que é o batismo infantil. A criança é batizada para que se expurgue o pecado original por meio do batismo.
}

Sapere aude - Belo Horizonte, v. 11 - n. 22, p. 577-588, Jul./Dez. 2020 - ISSN: 2177-6342 
respeito em suas criaturas, através delas. No segundo caso, eu não respeito as criaturas, nem Deus nelas. Eu as amo pelos interesses que posso obter, pelo uso que posso fazer delas. E eu instrumentalizo o próprio Deus em vista do meu benefício. A primeira forma de amor Agostinho chamou caritas ou dilectio. A outra, que instrumentaliza a Criação e o próprio Deus, ele chama de cupiditas ou concupiscentia ou libido. ${ }^{4}$

Dessa forma o desafio do homem em relação ao amor é, em Santo Agostinho, priorizar a caritas e deixar de lado a cupiditas, ou seja, o amor verdadeiro é o amor que tem o próprio Deus como objeto e que se identifica com o próprio Deus. "Deus caritas est” (I Jo 4,8), e é por isso que à medida que o homem ama em verdade mais em verdade ele se encontra no próprio Deus. $\mathrm{O}$ coração inquieto do homem encontra refúgio quando ama verdadeiramente a Deus. Para Santo Agostinho quando o homem encontra Deus ele encontra aquilo que lhe faltava. A partir do momento que o sujeito ama a Deus ele é capaz de amar a si mesmo e ao outro como pertencentes a Deus, e dessa forma seu coração se apazigua e ele alcança a felicidade, pois a felicidade está no próprio Deus.

Ao perceber que Deus não poderia ser buscado no que estava "fora de sua carne", Agostinho se volta para si, notando constituir-se de um corpo e uma alma, que o animam, oferecendo-lhe vida. Considerando-se apenas a materialidade do corpo, o homem pouco se difere do restante dos animais. Possuir uma alma, entretanto, o espiritualiza, dá a ele um elemento que o aproxima da realidade divina, por meio de princípios como a memória, por exemplo (mais adiante, a relação entre o espírito e a memória será mais aprofundada). Nessa perspectiva, o homem se encontra, hierarquicamente, posicionado entre Deus e os animais, uma vez que não se equipara ao Criador, por ser necessariamente criado, "originado em conformidade com as leis do tempo" (FERREIRA, 2012, p. 84), o que o configura como mutável, limitado e finito, diferentemente de Deus, mas ao mesmo tempo mostra-se superior aos outros animais, justamente por possuir uma alma. Portanto, não tendo encontrado Deus em corpos, Agostinho inicia uma série de ponderações que o levam ao estudo da mente e da memória e, consequentemente, do espírito.

\footnotetext{
${ }^{4}$ Esse tema do amor é bem desenvolvido por Hannah Arendt em sua dissertação de mestrado. Nesse trabalho Arendt (1997) explicita de maneira bastante didática a diferença entre a Caritas e a Cupiditas. Por uma questão de tamanho do artigo não será possível explorar a construção da autora.
} 
Eis que ascendo a ti, que permaneces acima de mim, passando pela minha mente: ultrapassarei até essa minha faculdade que chamam memória, querendo te alcançar por onde possas ser alcançado e me unir a ti por onde é possível se unir a ti. (AGOSTINHO, 2017, p. 273).

Nesse sentido, entende-se que Agostinho se inicia em uma jornada de autoconhecimento, por meio da contemplação das realidades visíveis e invisíveis e, principalmente, da racionalidade, com o objetivo de alcançar a Deus, confessando a Ele e ao leitor o que sabe e o que ignora de sua própria existência, como aponta Ferreira (2012), e entendendo sua posição em relação ao mundo e a ele mesmo. A narrativa de Confissões se mostra estratégica nesse ponto, uma vez que se dá por meio de uma interlocução com Deus que, por sua onisciência reconhecida pelo autor, já sabe o que lhe será "revelado". Sendo assim, o texto em si objetiva demonstrar o conhecimento de si mesmo à luz do tu absoluto, ou seja, Deus, expressão essa utilizada por Scherer (2006, p. 37), de forma a explicitar ao leitor os caminhos de Agostinho para a própria conversão, possibilitada por seu Criador, "o alicerce básico e fundamento da atividade cognoscitiva".

Para elaborar a ideia de memória, Agostinho refere-se espacialmente a tal faculdade da mente, atribuindo a habilidade ao espírito do homem, com a figuração de palácios e campos que guardam imagens de inúmeros objetos trazidas à mente por meio dos sentidos corporais. Esse processo se dá por meio de certa "duplicação" do objeto, uma vez que não o guardamos fisicamente na mente, mas apenas memorizamos sua forma. Assim, esse objeto passa a existir tanto no mundo físico, em suas dimensões reais, quanto na memória humana, na forma de imagem. Desse modo, as figuras dos objetos podem ser invocadas mesmo sem a presença física constante deles. Agostinho (2017, p. 272) comenta: "quando essas coisas estavam à mão, a memória captou as imagens delas, que percebi quando estavam presentes e trago de volta à mente quando as relembro ausentes".

Agostinho continua a discutir as habilidades da memória ao longo de exemplos como o da mulher que procura por uma dracma perdida, sendo essa faculdade da mente, como comenta Miranda (2001), um âmbito de acesso à verdade, possibilitada por sua relação com o uso dos sentidos. Se os sentidos não capturassem a imagem da moeda, mesmo que a encontrasse, a mulher não a reconheceria. Além das referidas imagens, o filósofo demonstra a presença de sensações, afetos e conhecimentos adquiridos ao longo da vida guardados também na memória, bem como sua relação com a medição do tempo. Os afetos podem ser entendidos como os 
sentimentos da alma, que carregam expressões distintas de acordo com o momento da recordação. Em outras palavras, a capacidade de guardar imagens permite que o homem relembre em sua mente, no presente, sensações já experienciadas um dia, sem que elas se expressem como em seus aspectos físicos ou emocionais originais. Como afirma Agostinho (2014, p. 166),

De fato, recordo-me de ter estado alegre, ainda que não o esteja neste momento, e lembro-me de minhas tristezas passadas, sem estar triste agora. Recordo-me de ter sentido às vezes medo, sem experimentá-lo agora, e me vem à mente um antigo desejo, sem que o sinta agora.

Por meio dessas considerações, é possível, novamente, entender a mente pela metáfora de sua espacialidade, além de sua vinculação com o corpo e com o espírito. Conceber a mente como um armazém, abre caminho para pensá-la como um território complexo que guarda, inclusive, lugares secretos e de difícil acesso, onde estariam "arquivadas" as lembranças mais difíceis de recobrar, influenciadas também pela imperfeição humana, limitadora do pleno uso das faculdades do ser. Como aponta Agostinho (2017, p. 269), "realmente, então, a memória é como um estômago da mente, a alegria e a tristeza como alimentos doces e amargos: quando são enviados à memória, podem ser depositados ali como dentro de um ventre, mas não podem conservar o sabor." Em relação ao espírito, é possível considerar que esse é o maior responsável pela capacidade de lembrar, uma vez que, como mostra Ferreira (2012, p. 87), "é em seu reino que as coisas se tornam presentes e passíveis, assim, de serem mensuradas."

Por fim, o filósofo afirma também guardar, na memória, os ensinamentos que recebeu ao longo da vida, sendo importante, aqui, considerar que as lembranças não dependem unicamente dos sentidos. "Com efeito, a imagem não é essencial à recordação." (MIRANDA, 2001, p. 229), de forma que recorda-se dos aprendizados, bem como dos debates que julgavam a veracidade de tais conhecimentos. Mesmo que tidos como falsos, Agostinho demonstra que o fato de lembrar-se deles não pode ser contestado, ou seja, a refutação do conhecimento não faz com que esse deixe de existir. $\mathrm{O}$ argumento apenas sobrevive na forma de uma inverdade, na memória. A exemplo disso, tem-se a referenciação recorrente que a obra Confissões faz à dedicação de Agostinho à astrologia. Os conhecimentos adquiridos de tais estudos, mais tarde, se mostraram infundados para o autor, mas a recordação de um dia tê-los crido permanece. 
Outro ponto importante a ser abordado trata da relação entre a memória e o tempo. Considerando o tempo como uma constante sucessão de presentes, entende-se que o homem vive cada instante em uma dimensão passageira: o presente torna-se passado antes que seja possível pensá-lo. "Um tempo longo não poderia ser longo senão por muitos movimentos passageiros, que não poderiam se estender simultaneamente." (AGOSTINHO, 2017, p. 316).

Dessa forma, ao homem só é factível pensar em situações passadas, já registradas por suas imagens na memória tal como ocorreram em algum presente, uma vez que a brevidade do tempo presente torna impossível sua reflexão, ao mesmo tempo que momentos passados, presentes e futuros não podem coexistir. Nesse sentido, a partir da associação e recombinação da bagagem de memórias e conhecimentos, o homem torna-se capaz de produzir novos pensamentos, apenas com base no que já experienciou. Assim, o passado se transforma em memória, e o futuro se torna expectativa; e ao homem cabe apenas o tempo presente.

Levando em conta a já explicitada limitação humana de apenas pensar situações passadas, Agostinho passa a refletir sobre as condições para a felicidade. É verdade universalmente reconhecida que qualquer homem, em posse ou não de boa fortuna, está em busca da vida feliz. Mas onde ela poderia ser encontrada? O desejo de experienciá-la é comum a todos os homens, mas "onde a conheceram, se a querem tanto? Onde a viram, para amá-la?" (AGOSTINHO, 2017, p. 275). Tendo em mente que o homem de muitas posses não pode ser feliz, por sempre temer a perda de seu patrimônio, como demonstra o livro Sobre a vida feliz, do mesmo autor, entende-se que a felicidade está condicionada apenas à busca da verdade, imutável e eterna, ou seja, a vida feliz está intrinsecamente ligada ao relacionamento com Deus, o único perpétuo e inabalável, pois, como afirma Agostinho (2014, p. 19), "de modo algum duvidamos que alguém decidido a ser feliz deve tentar alcançar algo que seja perene, que não possa ser-lhe roubado por algum tipo de acaso incontrolado".

Em suma, apreende-se que todos os homens guardam na memória vestígios de uma vida feliz com Deus, além da ideia do próprio Deus, uma vez que, para o filósofo, se podemos pensála, amá-la e desejá-la, é por guardarmos uma lembrança da referida situação. O mesmo se apresenta para Deus: "Se te encontro além da memória, sou imêmore de ti. E como te encontrarei, se não me lembrar de ti?" (AGOSTINHO, 2017, p. 273). 
Reconhecendo a possibilidade da existência de tal lembrança, ainda nos restam os seguintes questionamentos: por que não temos uma imagem nítida da ocasião? A que momento a recordação faz referência? Para respondê-los, é preciso seguir na análise de Confissões. Ainda no livro X, Agostinho mostra que a vida feliz não pode ser captada pelos sentidos físicos, uma vez que sua lembrança ultrapassa a materialidade. "Não: a vida feliz não se vê pelos olhos, porque não é um corpo." (AGOSTINHO, 2017, p. 276). Dessa forma, compreende-se que a felicidade é recobrada pela mente tal como os sentimentos da alma, que independem do que é corpóreo, sem que tenha-se uma imagem real dela:

Lembro meu regozijo mesmo quando triste, assim como lembro a vida feliz sendo infeliz; e com nenhum sentido do corpo vi ou ouvi ou cheirei ou gostei ou toquei meu prazer, mas o experimentei em minha mente, quando estive alegre, $\mathrm{e}$ fixei a noção dele em minha memória, para que pudesse lembrá-lo. (AGOSTINHO, 2017, p. 276).

Prosseguindo para o segundo ponto, Agostinho ainda cita duas condições para a experiência primeira da vida feliz: ou todos os homens foram felizes individualmente, um dia, ou fomos todos felizes no primeiro homem, a partir do qual todos nasceram infelizes, em pecado. Entretanto, essa questão não é aprofundada no capítulo em estudo, mas pode-se afirmar que, em ambos os casos, a lembrança de um contexto experienciado pelo espírito ainda seria armazenada na memória, não como uma imagem, mas configurando uma expectativa constante, um desejo insaciável senão pelo relacionamento com a única verdade: Deus. Com tal posicionamento a respeito da memória da vida feliz, Agostinho se afasta da teoria da reminiscência platônica, na qual a alma não se recorda do conhecimento do mundo inteligível ${ }^{5}$. O fato de não conseguirmos nos lembrar com clareza de tal momento se deve à limitação da própria natureza humana, que é imperfeita, sofrendo, como o homem em si, os efeitos da passagem do tempo: o esquecimento, tema também abordado pelo filósofo. Enfim, embora alguns procurem a satisfação de tal ânsia

\footnotetext{
${ }^{5}$ Um ponto importante a se marcar aqui é exatamente esse afastamento de Agostinho a respeito da doutrina da reminiscência de Platão. A proposta da reminiscência descrita por Platão em diversos diálogos tais como Mênon, A república, Teeteto, Fédon, dentre outros, pressupõe a ideia de imortalidade da alma e a noção de reencarnação (muito bem recebida pelos gregos a partir do orfismo). Agostinho, mesmo tendo tido forte influência da filosofia de Platão e do neoplatonismo, é profundamente cristão nesse ponto. O cristianismo nunca aceitou a noção de reencarnação da alma, mas sim a doutrina da ressurreição do corpo. Neste ponto, ainda que haja algum tipo de memória da vida feliz em Santo Agostinho, isso está longe de pressupor uma vida da alma anterior ao seu pertencimento ao corpo. A noção de memória em Santo Agostinho se liga à antropologia cristã de um homem criado por Deus em perfeita harmonia com Ele, mas que por livre escolha comete o pecado que tem como consequência o afastamento de Deus para quem o homem deseja retornar. A memória da vida feliz, portanto, se insere dentro dessa antropologia em Agostinho.
} 
"aqui, outros ali, mesmo assim, aquilo que todos desejam alcançar é único: o regozijo" (AGOSTINHO, 2017, p. 277).

Por fim, e seguindo na temática do amor, Agostinho passa a refletir sobre os pecados que o homem escolhe amar, muitas vezes, no lugar de Deus. Afirma que algumas imagens de hábitos pecaminosos permanecem também armazenados na memória, e que retornam à lembrança, mesmo que contra a vontade, tentando sua carne seja acordado, durante o dia, seja por meio de sonhos. Deus não seria capaz de livrá-lo dos pecados que comete, contra a própria vontade, em tais sonhos? Como seria possível concordar com o mal durante o sono? Nisso, Agostinho pede que Deus o fortifique com dons divinos, "para que minha alma siga em direção a ti e para que o sono não apenas me perpetre, pelas imagens sensuais, essas torpezas de corrupção, até o fluxo carnal, mas nem sequer o consinta" (AGOSTINHO, 2017, p. 283), uma vez que, ainda segundo ele, é impossível ser continente sem a permissão de Deus.

Já no "mal do dia", como se refere, Agostinho aborda costumes que se tornam pecaminosos pelo excesso, como o comer e o beber, que tentam equilibrar-se em linhas tênues entre a necessidade da saúde e o prazer concupiscioso, entre a fome e a gula, a sede e a embriaguez. A necessidade física provocada por jejuns, que objetivam reduzir o corpo à servidão, ou pela própria inevitabilidade da biologia humana, rapidamente se torna prazer pela simples e até moderada saciedade. "Com efeito, a própria passagem é um prazer, e não há outra pela qual passar, quando a necessidade a força a passar." (AGOSTINHO, 2017, p. 285). É importante ressaltar, aqui, que o pecado e a impuridade não estão na comida ou na bebida, mas no desejo. "Mas sei que Esaú foi logrado pelo desejo de lentilhas e Davi repreendia a si mesmo por querer água, e nosso rei foi tentado não com carne, mas com pão." (AGOSTINHO, 2017, p. 287).

Tal como o comer e o beber, Agostinho pondera sobre a concupiscência dos perfumes, da musicalidade, da beleza e do conhecimento. No primeiro caso, o filósofo não considera que o prazer das fragrâncias chegue a tentá-lo, e acredita poder, talvez, viver sem elas para sempre. Entretanto, para ele, as "volúpias do ouvido", presentes nas canções das vozes suaves, trazem maior satisfação, não necessariamente ao ponto de fazê-lo pecar por vícios, mas ao ponto de destacar a iminência da possibilidade de tal falta. O prazer que as melodias trazem para Agostinho, muitas vezes supera a razão pura da compreensão do texto sagrado em exposição, como os cânticos dos Salmos de Davi, em que a forma ou o canal pode se sobrepor ao conteúdo 
da mensagem, o que configura, em si, um pecado sutil, que passa despercebido até que o regozijo se finde. Em uma tentativa desesperada de evitar o pecado pelos ouvidos, tenta afastar-se de toda forma de musicalidade, mas o exagero também configura um erro, uma vez que a música, em um equilíbrio complementar com a palavra, é capaz de emocionar e transformar.

Porém, quando relembro as lágrimas que verti ouvindo o canto da igreja no começo da reconquista de minha fé, e quando ainda hoje me comovo, não pelo canto, mas pelas coisas que se cantam com voz fluente e modulação perfeita, volto a reconhecer a grande utilidade dessa instituição. Oscilo, assim, entre o perigo do prazer e a experiência da salvação e me inclino, ainda que não por um julgamento inabalável, a me pronunciar a favor do hábito de cantar na igreja, para que, pelos deleites do ouvido, a alma mais fraca se aproxime do sentimento religioso. (AGOSTINHO, 2017, p. 290).

Em conclusão à questão dos sentidos, Agostinho trata do prazer dos olhos, por meio dos quais é possível amar as formas belas e variadas, as cores claras e amenas, como a última das concupiscências da carne. Diferentemente dos perfumes e dos sons, a luz destaca todos os tipos de delineamentos graciosos durante o dia, tentando-o constantemente, convidando-o a prestar um pouco mais de atenção. A luminosidade física "se insinua com tal força que, se for subtraída de repente, a busco com desejo; e se faltar por muito tempo, a mente se entristece" (AGOSTINHO, 2017, p. 291). A volúpia dos olhos se encontra em roupas e calçados produzidos por artesãos, vasos, pinturas, e moldagens variadas e, em suma, em tudo aquilo que ultrapassa a necessidade, tentando os sentidos com uma beleza não prática ou essencial. Por meio do sentido da visão também é possível conhecer, produzir ciência e, nesse sentido, aborda-se o conhecimento como uma forma de tentação mais rica em perigos, pelo desejo por experiências, motivado pela curiosidade desenfreada por coisas, na maior parte das vezes, ínfimas.

É também por isso que, pelo mesmo fim de um conhecimento depravado, fazemos investigações por meio das práticas da magia. Ainda por isso, na própria religião, tentamos Deus reclamando dele sinais e prodígios, não por algum escopo salutar, mas apenas por desejo de experiência. (AGOSTINHO, 2017, p. 294).

Por fim, ao final do capítulo $\mathrm{X}$, trata-se dos dons concedidos por Deus aos homens e algumas últimas situações em que o orgulho impõe sua sombra. Segundo Agostinho, por meio daqueles, os homens se fazem amados ou temidos. Contudo, encontra-se aqui mais um último 
gênero de tentação a ser abordado, no qual deseja-se o amor ou o temor alheio não por fins específicos ou para a glorificação do Criador, mas pela simples satisfação do próprio ego. Assim,

o inimigo de nossa verdadeira felicidade espalha por toda parte em suas armadilhas gritos de 'Bravo! Bravo!', para que, colhendo-os, avidamente, incautos, sejamos capturados e desviemos nosso prazer de tua Verdade e o depositemos nas falácias dos homens, gostando de ser temidos não por causa de ti, mas em teu lugar, [...] (AGOSTINHO, 2017, p. 297).

Aqui, entende-se a importância de se apreciar o dom divino manifestando-se nas ações humanas, e não os talentos humanos como elementos isolados, nem suas obras desvinculadas da concessão de Deus. Além disso, tais habilidades, pondera Agostinho, não devem ser usadas unicamente pelo proveito próprio, mas sim pelo bem que podem fazer ao próximo. Em se tratando do orgulho, incitado por tais exaltações fúteis aos dons, quando direcionadas especificamente ao homem, o autor também evidencia outra condição de amor ao louvor, em que, mesmo ao confessar-se, é glorificado por envergonhar-se de sua própria vanglória.

\section{CONCLUSÃO}

Os temas do amor e da memória são de grande importância para a filosofia agostiniana, de forma que, como já mencionado, tentar abordar toda a teoria do autor aqui seria impensável. Em vista disso, no presente artigo optamos por trazer maior enfoque sobre o exposto no livro $\mathrm{X}$ de Confissões, perpassando pelo reconhecimento da existência da alma nos homens, sua relação com a memória, as nuances dessa faculdade da mente e, por fim, as volúpias dos sentidos, que seduzem os homens e os afastam do amor à Verdade. Tais temas da memória e do amor são importantes para as Confissões, bem como para a filosofia agostiniana como um todo, de forma que uma análise desses temas se mostra importante e ajuda na compreensão da ampla filosofia agostiniana.

\section{REFERÊNCIAS}

AGOSTINHO. Confissões. 2. ed. São Paulo: Paulus, c1997. (Patrística, 10).

AGOSTINHO. Confissões. 2. ed. São Paulo: Penguin Classics Companhia das Letras, 2017. 
AGOSTINHO. A graça I. Sao Paulo: Paulus, 1999. (Patrística, 12).

AGOSTINHO. Soliloquios e a vida feliz. 2. ed. São Paulo: Paulus, 1998. (Patristica, 11).

AGOSTINHO. A verdadeira religião. O cuidado devido aos mortos. São Paulo: Paulus, 2002. (Patrística, 19).

ARENDT, Hannah. O conceito de amor em Santo Agostinho: ensaio de interpretação filosófica. Lisboa: Instituto Piaget, 1997. (Pensamento e filosofia, 13).

BÍBLIA SAGRADA. Tradução NVI. Local: Editora Vida. 2000.

FERREIRA, Leonardo Almada. Sobre a indissociabilidade entre tempo e memória em Santo Agostinho. Revista Ágora Filosófica, [S.1.], v. 1, n. 1, mar. 2012. p. 77-88 (2007).

MIRANDA, José Carlos de. A memória em S. Agostinho - Memoria Rerum, Memoria Sui, Memoria Dei. Humanitas, v. 53. p. 226-247, 2001.

PLATÃO. O banquete. Mira-Sintra: Publicações Europa-America, 1977. (Livros de bolso Europa America, 168).

SCHERER, Fábio César. Memória e interioridade nas Confissões. Controvérsia, v. 2. p. 68-91, 2006. 